\title{
Confirmatory experiments for nuclear emissions during acoustic cavitation
}

\author{
Yiban $\mathrm{Xu}^{\mathrm{a}, *}$, Adam Butt ${ }^{\mathrm{a}, \mathrm{b}}$ \\ ${ }^{a}$ School of Nuclear Engineering, Purdue University, West Lafayette, IN 47907 USA \\ ${ }^{\mathrm{b}}$ School of Aeronautical and Astronautical Engineering, Purdue University, West Lafayette, IN 47907 USA
}

Received 13 January 2005; received in revised form 14 January 2005; accepted 7 February 2005

\begin{abstract}
Confirmatory experiments were conducted to assess the potential for nuclear fusion related emissions of neutrons and tritium during neutron-seeded acoustic cavitation of deuterated acetone. Corresponding control experiments were conducted with normal acetone. Statistically significant (5-11S.D. increased) emissions of $2.45 \mathrm{MeV}$ neutrons and tritium were measured during cavitation experiments with chilled deuterated acetone. Control experiments with normal acetone and irradiation alone did not result in tritium activity or neutron emissions. Insights from imaging studies of bubble clusters and shock trace signals relating to bubble nuclear fusion are discussed.

Published by Elsevier B.V.
\end{abstract}

\section{Introduction}

It is well-known (Gross, 1984) that the thermonuclear fusion of deuterium (D) atoms requires high pressures, high temperatures and sufficient length of confinement time. The intense implosive collapse of bubbles, including acoustic cavitation bubbles, can lead to extremely high compressions and temperatures, and

Abbreviations: DPM, disintegrations per minute; PNG, pulse neutron generator; PRE, proton recoil edge; PSD, pulse shape discrimination; S.D., standard deviation; SL, sonoluminescence

* Corresponding author.

E-mail addresses:yiban@purdue.edu (Y.Xu),butt@purdue.edu (A. Butt). to the generation of light flashes attributed to sonoluminescence and involves energy focusing of $\sim 10^{11}$ (Crum and Matula, 1997; Camara et al., 2004). The possibility of using the phenomenon of sonoluminescence for attaining thermonuclear fusion in collapsing gas-vapor cavities has been predicted theoretically as a possibility if appropriate techniques and methodologies were discovered and developed to lead to intenseenough compressions and heating (Moss et al., 1996; Nigmatulin et al., 2004; Taleyarkhan et al., 2004b). Taleyarkhan et al. $(2002,2004 a)$ provided experimental evidence of such nuclear emissions using the novel experimental technique and approaches they developed. In this methodology, neutrons are used (much like in a conventional fission reactor where neutrons inter- 
act with uranium nuclei and produce more neutrons) to seed nanometer size vapor bubbles in a tensioned organic liquid (acetone) which then grow by factors of $\sim 100,000$ and then intensely implode to produce flashes of sonoluminescence light accompanied with intense localized pressures, and temperatures for the compressed vapor molecules. In a deuterated liquid, the approach resulted in evidence of statistically significant neutron and tritium emissions (Taleyarkhan et al., 2002, 2004a,b).

The aim of the present study and experiments was to confirm if, by following the cited conditions and methodology by Taleyarkhan et al. (2002, 2004a) that nuclear fusion signatures (i.e., statistically significant $\leq 2.45 \mathrm{MeV}$ neutrons and tritium emissions) can result during neutron-seeded acoustic cavitation of $\mathrm{C}_{3} \mathrm{D}_{6} \mathrm{O}$ at $\sim 0{ }^{\circ} \mathrm{C}$, but not with neutron irradiation alone, nor while conducting corresponding neutronseeded acoustic cavitation experiments with $\mathrm{C}_{3} \mathrm{H}_{6} \mathrm{O}$ since thermonuclear fusion of $\mathrm{H}$-atoms is not possible (Gross, 1984).

\section{Experiment set-up}

Following the methods and apparatus dimensions reported in the published literature (Taleyarkhan et al., 2002, 2004a), a test cell $(\sim 62 \mathrm{~mm}$ in diameter and $\sim 200 \mathrm{~mm}$ in height) made of Pyrex ${ }^{\mathrm{TM}}$ driven with a cemented PZT piezoelectric driver ring was constructed. The system was driven with a $40 \mathrm{~W}$ PiezoSystems $^{\mathrm{TM}}$ linear amplifier and a Agilent $^{\mathrm{TM}}$ wave-form generator as shown schematically in Fig. 1. Experiments were conducted to assess if neutrons and/or tritium emissions occur when conducting neutron-seeded acoustic cavitation experiments with deuterated acetone $\left(\mathrm{C}_{3} \mathrm{D}_{6} \mathrm{O}\right.$, certified 99.92 at\% D). Corresponding control experiments were also devised without cavitation (i.e., neutron irradiation alone) as well with neutron-seeded cavitation in normal acetone $\left(\mathrm{C}_{3} \mathrm{H}_{6} \mathrm{O}, 100 \%\right.$ pure $)$. The negative pressure threshold for bubble nucleation by fast neutrons in acetone is -7 to -8 bar (Hahn, 1961). A pressure map of the chamber was obtained by means of a calibrated hydrophone. The drive voltage corresponding to the onset of cavitation (defined herein as the onset of nucleation and collapse of bubbles within a $10 \mathrm{~s}$ observation period) in the presence of neutrons was first determined to get a state point corresponding to $\sim \pm 7$ bar magnitude, and then doubled (as done by Taleyarkhan et al., 2002) to obtain the approximate drive pressure amplitudes of \pm 15 bar for conduct of the confirmatory experiments.

Unlike the experiments conducted by Taleyarkhan et al. $(2002,2004 a)$ where precise time-based nucleation was performed with a $14 \mathrm{MeV}$ pulse neutron generator (PNG), such apparatus was not available for the present study. Due to this unavailability seeding of bubbles was conducted using an available isotope neutron source. This is considered reasonable since the present study was not focused on timing of sonoluminescence flashes and time-correlation of emitted neutrons with sonoluminescence, etc., but to investigate if the key nuclear fusion signatures $(2.45 \mathrm{MeV}$ neutrons and tritium) are possible to detect in statistically significant quantities with neutron-seeded cavitation of $\mathrm{C}_{3} \mathrm{D}_{6} \mathrm{O}$. The acoustic driving system, filtration (with $1 \mu \mathrm{m}$ filters $)$, degassing and system pressure $(\sim 10 \mathrm{kPa})$ were kept similar to that used in the Taleyarkhan et al. (2002, 2004a) experiments. Upon test cell construction, liquid degassing and performance characterization it was confirmed via counting microphone shock trace histories that $\sim 10-20$ bubble clusters could be generated per second with a drive amplitude of $\sim \pm 15$ bar and a resonance frequency of $\sim 19.6 \mathrm{kHz}$ for $\mathrm{C}_{3} \mathrm{D}_{6} \mathrm{O}$ and about $20.6 \mathrm{kHz}$ for $\mathrm{C}_{3} \mathrm{H}_{6} \mathrm{O}$. Although the bubble cluster activity was not as high as reported (Taleyarkhan et al., 2002, 2004a), this performance was considered adequate for overall confirmatory purposes.

As is well-known, the fusion of D atoms (Gross, 1984) results in the emission of a proton, helium-3, a neutron (of $2.45 \mathrm{MeV}$ energy) and tritium. Protons (in the $\mathrm{MeV}$ range) are charged particles which cannot traverse more than $\sim 1 \mathrm{~mm}$ in the liquid before getting absorbed, and therefore, cannot be measured with detectors outside of the apparatus. The same problem holds true for helium-3 atoms which are nonradioactive and difficult to detect in small quantities. Neutrons are uncharged particles which can leak out of the test chamber and can be detected with suitable instrumentation. Also, tritium being a radioactive gas which remains in the test liquid can be counted for beta-decay activity (if a suitable state-of-the-art beta spectrometer is available). Therefore, testing was initiated systematically for monitoring the key signatures consisting of tritium and neutron emissions. 


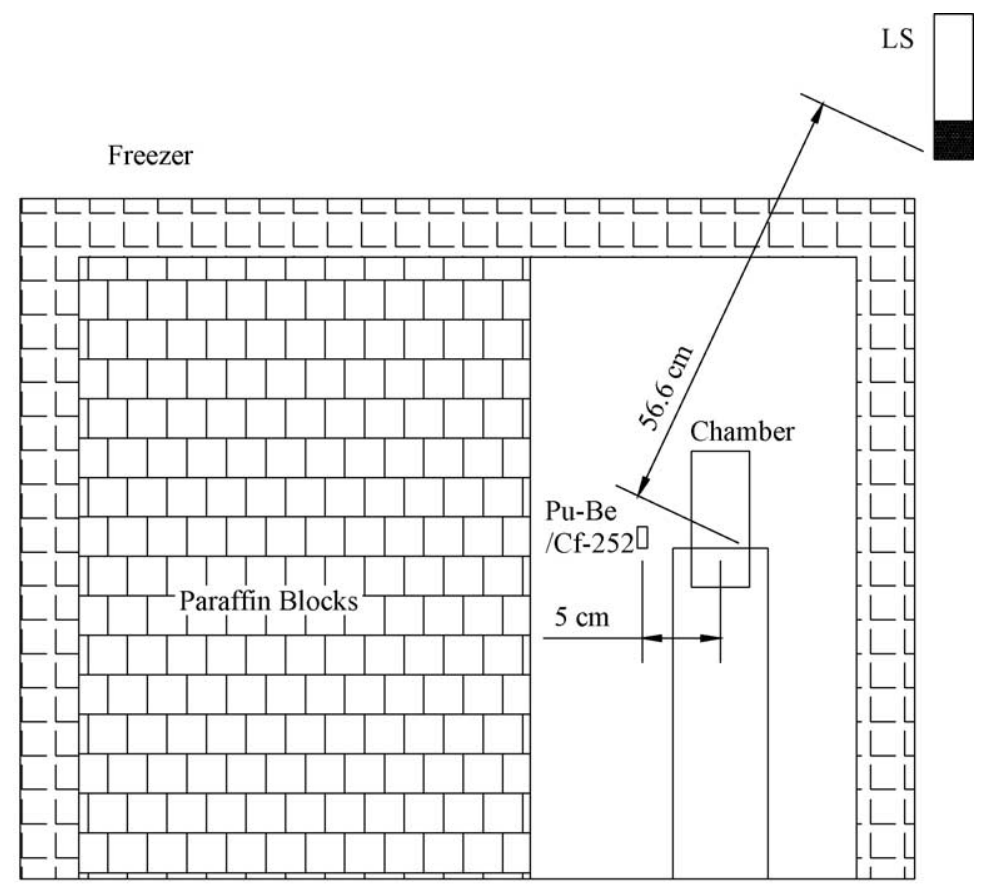

(a)

Layout of experimental apparatus

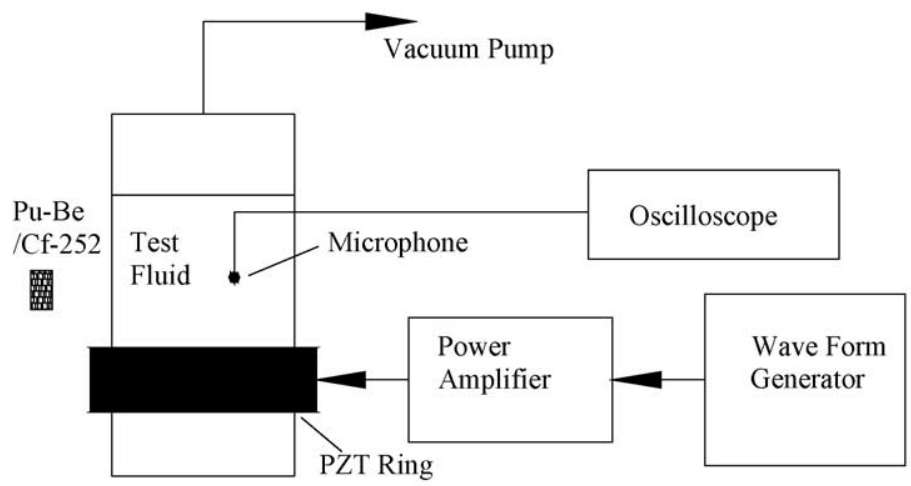

(b)

Test cell and acoustic drive chain

Fig. 1. Schematic of experimental apparatus.

\section{Tritium detection experiments}

Tests were first conducted to confirm if statistically significant quantities of tritium are generated only when conducting neutron-seeded cavitation in $\mathrm{C}_{3} \mathrm{D}_{6} \mathrm{O}$. For these experiments a $1 \mathrm{Ci} \mathrm{Pu}-\mathrm{Be}$ neutron source (emitting about $2 \times 10^{6} \mathrm{n} / \mathrm{s}$ ) was available and there- fore, utilized. The test cell (maintained at $\sim 0{ }^{\circ} \mathrm{C}$ temperature) was placed in a closed freezer, which was furthermore, surrounded with paraffin blocks for radiological safety. A schematic of the experimental arrangement is shown in Fig. 1 along with the relative position of the $\mathrm{Pu}-\mathrm{Be}$ neutron source. Tests were conducted with neutron irradiation alone, followed with tests 
with neutron-seeded cavitation-systematically changing only one parameter at a time. Neutron-seeded acoustic cavitation was conducted for $\sim 6 \mathrm{~h}$ duration. Liquid samples were taken before and after cavitation from the liquid poured into the same test chamber. For each sample $1 \mathrm{~cm}^{3}$ of acetone was pippetted and mixed with $15 \mathrm{~cm}^{3}$ of Ultima Gold ${ }^{\mathrm{TM}}$ scintillation cocktail in a borosilicate glass vial. Each vial was counted for $100 \mathrm{~min}$ for tritium beta decay activity (i.e., in the $5-19 \mathrm{keV}$ energy emission window) in a calibrated Beckman LS6500 ${ }^{\mathrm{TM}}$ liquid scintillation counter. Results of tritium activity changes are displayed in Fig. 2. As the legend indicates, tritium data for neutron-seeded cavitation tests for $6 \mathrm{~h}$ with $\mathrm{C}_{3} \mathrm{D}_{6} \mathrm{O}$ are displayed using solid diamond symbols, whereas solid triangles represent data obtained with $6 \mathrm{~h}$ neutron irradiation (without cavitation) for $\mathrm{C}_{3} \mathrm{D}_{6} \mathrm{O}$. Data obtained for the $6 \mathrm{~h}$ control tests with neutron-seeded cavitation of $\mathrm{C}_{3} \mathrm{H}_{6} \mathrm{O}$ are displayed with solid square symbols. It is seen that a statistically significant increase ( $\sim 4-5$ S.D.) of tritium is only observed for tests with neutron-seeded cavitation of $\mathrm{C}_{3} \mathrm{D}_{6} \mathrm{O}$. For neutronseeded cavitation tests with the control liquid $\mathrm{C}_{3} \mathrm{H}_{6} \mathrm{O}$, as well as for tests with neutron irradiation of $\mathrm{C}_{3} \mathrm{D}_{6} \mathrm{O}$ the tritium activity changes are within 1S.D. One of the four $6 \mathrm{~h}$ tests with neutron-seeded cavitation of $\mathrm{C}_{3} \mathrm{D}_{6} \mathrm{O}$ resulted in no increase of tritium activity. This appears to have been due to the occurrence of significant and persistent $(>30 \mathrm{~ms})$ comet-like (see discussion in a later section) bubble streams composed of tiny $(\ll 1 \mathrm{~mm})$ bubble clouds during this particular test alone and not the intensely imploding short-lived $(<5 \mathrm{~ms})$ individual and large $(\sim 6 \mathrm{~mm})$ spherical bubble clusters required for high-temperature and compression states as was the case for the other remaining three tests. Notably, for the other three remaining $6 \mathrm{~h}$ tests with $\mathrm{C}_{3} \mathrm{D}_{6} \mathrm{O}$ large bubble cluster implosions were present not comet-like bubble streams. Therefore, it appears that small-dimension collapsing cavitation bubbles in a comet-like configuration are not conducive for generating intense-enough nuclear fusion conditions and is in line with proposed theory (Nigmatulin et al., 2004).

\section{Neutron emission measurements}

Upon acquisition of neutron detection equipment tests were also initiated for monitoring changes in neutron activity with and without cavitation using the same closed freezer compartment and acoustic drive train. However, a short while after completing the experiments for tritium monitoring the experiment location had to be shifted to a new building off-campus where the $1 \mathrm{Ci} \mathrm{Pu}-\mathrm{Be}$ isotope neutron source could not be relocated. Instead, a $0.5 \mathrm{mCi} \mathrm{Cf-252}$ isotope neutron source was available for use. Also, a new test cell (which could produce a relatively lower approximately $<10$ bubble clusters per second) had to be constructed due to mechanical breakage that developed in the first test cell. A liquid scintillation

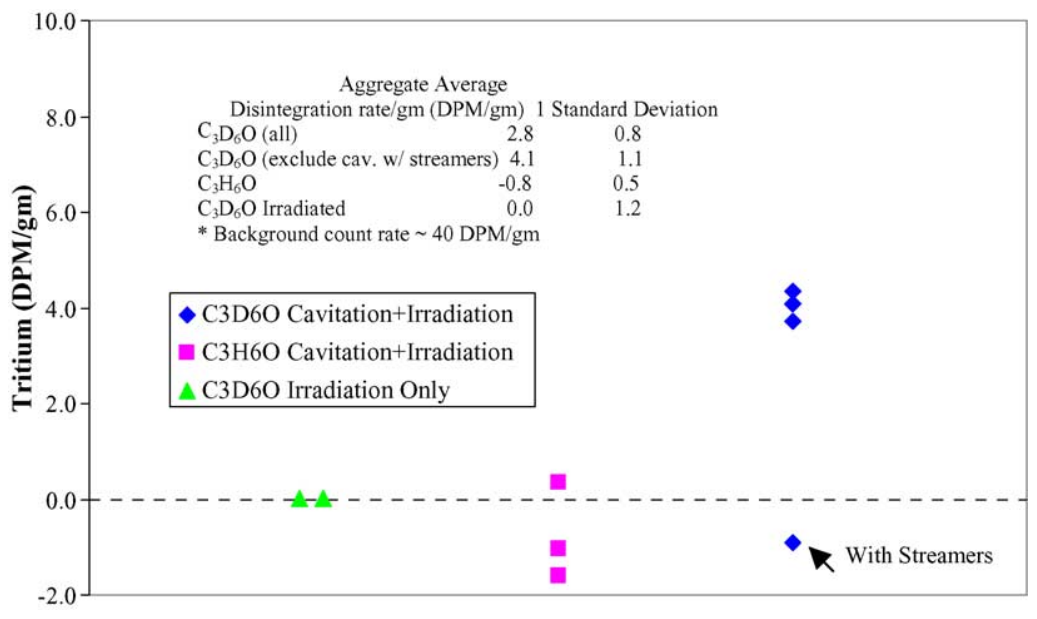

Fig. 2. Results of tritium counting. 


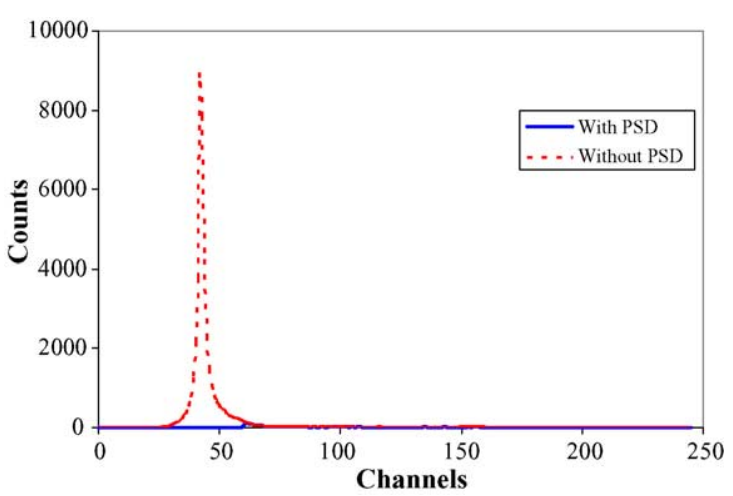

Fig. 3. Pulse shape discrimination (PSD) for gating out gamma ray emissions (using mono-energetic Co-60 source).

(LS) detector from Eljen Technologies Inc. (NE-213 type liquid-based, $5 \mathrm{~cm} \times 5 \mathrm{~cm}$ ) was procured and used for neutron detection with data acquisition electronics as reported earlier (Taleyarkhan et al., 2004a). Standard pulse shape discrimination (PSD) techniques (Harvey and Hill, 1979) were utilized using an Ortec552 pulse shape analyzer to gate out gamma rays, as shown in Fig. 3 (where it is seen that the gamma rays component can be convincingly discriminated). For evaluating the proton recoil edge corresponding to $2.45 \mathrm{MeV}$ neutron energy during pulse-height data acquisition calibration was conducted using Co60 and Cs-137 monoenergetic gamma sources. The respective pulse height spectra are shown in Fig. 4 from which the $2.45 \mathrm{MeV}$ proton recoil edge was estimated (Harvey and Hill, 1979) to lie around channel 85. The neutron pulses from the LS detector were recorded by a UCS- $20^{\mathrm{TM}}$ multichannel analyzer (from Spectrum Techniques Inc.). Typical raw pulse-height data (for total counts collected in individual channels) are depicted in Fig. 5 for $\mathrm{C}_{3} \mathrm{H}_{6} \mathrm{O}$ and $\mathrm{C}_{3} \mathrm{D}_{6} \mathrm{O}$, respectively, with and without cavitation in the presence of the neutron source-keeping all parameters the same between the control experiment and experiments with the deuterated liquid. Notably, it is seen from Fig. $5 \mathrm{c}$ that $\sim 50 \%$ excess counts (over background) increase takes place only for neutronseeded cavitation tests with $\mathrm{C}_{3} \mathrm{D}_{6} \mathrm{O}$; this mainly occurs at and below channel 85, implying that the neutrons being emitted during cavitation are $\leq 2.45 \mathrm{MeV}$. The variation of counts difference between cavitation on and off for the control liquid $\mathrm{C}_{3} \mathrm{H}_{6} \mathrm{O}$ was found to be random in nature around the zero line. In relation to Fig. $5 \mathrm{c}$ for over $25 \mathrm{~s}$ of collection time, 2391 counts, and 1629 counts were collected with and without cavitation, respectively, using $\mathrm{C}_{3} \mathrm{D}_{6} \mathrm{O}$ as the test fluid in the presence of a $0.5 \mathrm{mCi} \mathrm{Cf}-252$ source at the same position. Assuming Poisson statistics, 1S.D. of counts $=(2391+1629)^{1 / 2}=\sim 63$. Therefore, the change in counts of about $762(=2391-1629)$ amounts to a statistically significant increase of $\sim 11$ S.D. $(=762 / 63)$.

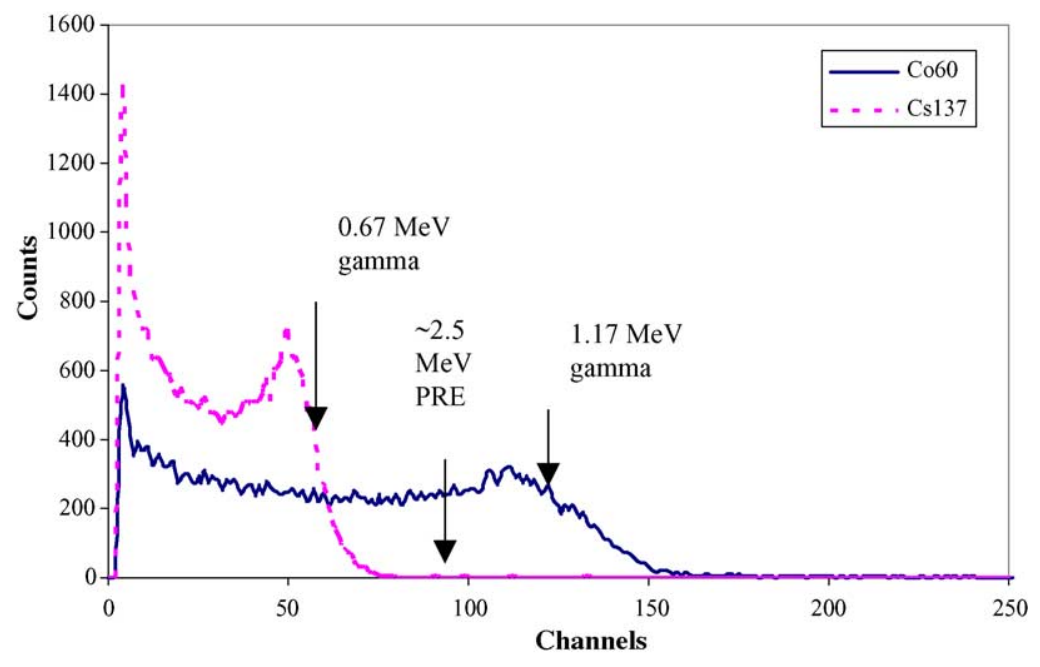

Fig. 4. Calibration of liquid scintillation detector to determine the $2.5 \mathrm{MeV}$ proton recoil edge. 

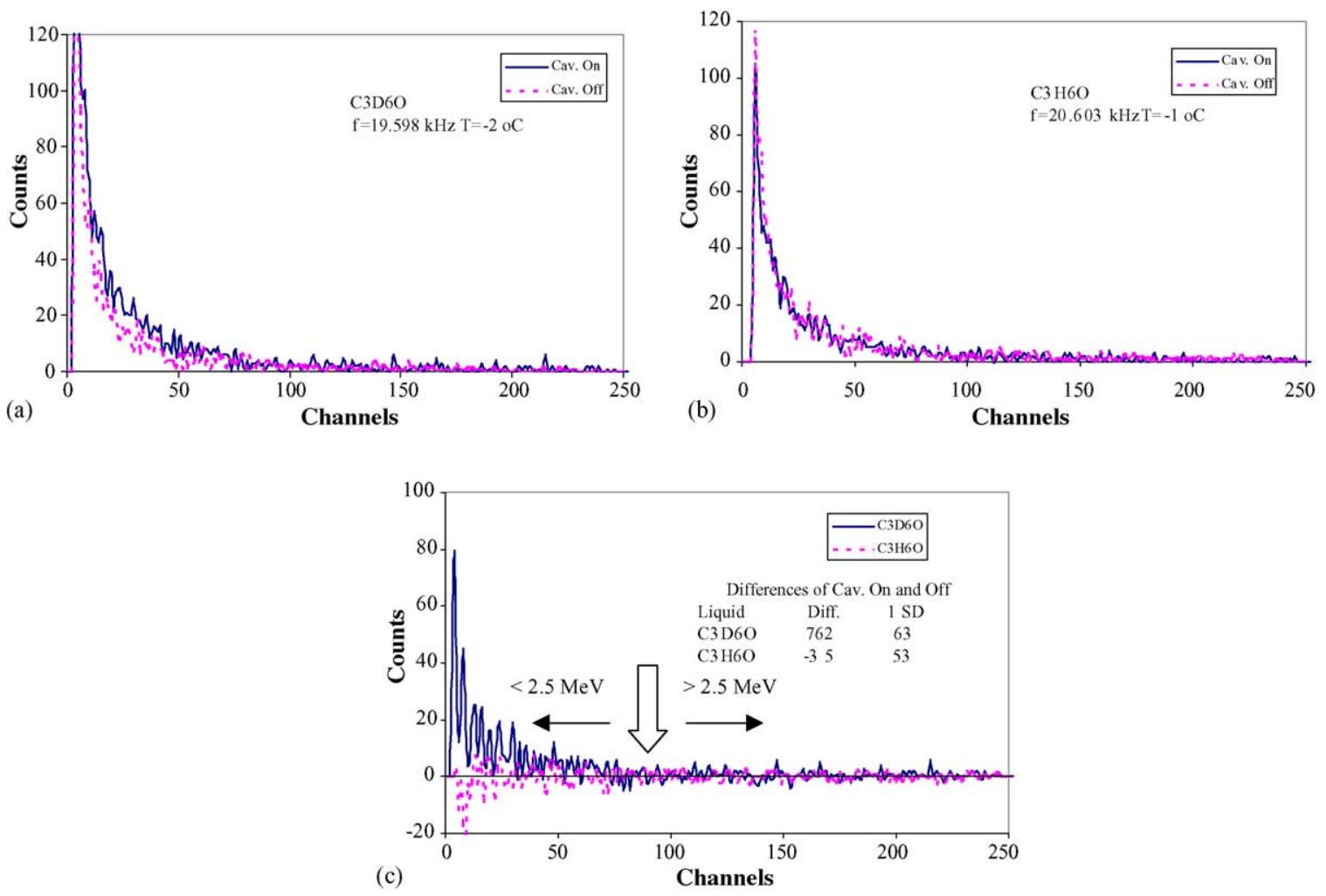

Fig. 5. (a) Representative neutron gated counts below and above $2.5 \mathrm{MeV}$ proton recoil edge for tests with $\mathrm{C}_{3} \mathrm{D}_{6} \mathrm{O}$ at $\sim 0{ }^{\circ} \mathrm{C}$ with and without cavitation; (b) representative neutron gated counts below and above $2.5 \mathrm{MeV}$ proton recoil edge for tests with $\mathrm{C}_{3} \mathrm{H}_{6} \mathrm{O}$ at $\sim 0{ }^{\circ} \mathrm{C}$ with and without cavitation; (c) representative neutron gated counts below and above $2.5 \mathrm{MeV}$ proton recoil edge for tests with $\mathrm{C}_{3} \mathrm{D}_{6} \mathrm{O}$ and $\mathrm{C}_{3} \mathrm{H}_{6} \mathrm{O}$ at $\sim 0{ }^{\circ} \mathrm{C}$ with and without cavitation.

\section{Insights into bubble dynamics behavior and possible influence on bubble fusion}

During system characterization testing imaging of bubble formation and evolution was also conducted. In addition, a microphone was attached to the test cell walls to record the amplitude of shock waves generated during implosion of the bubbles (which in effect send acoustic perturbations in the liquid and can be picked up when they reach the glass walls of the test chamber). It has been postulated (Brennan, 1995) that large bubbles in the $1 \mathrm{~mm}$ range can break apart into clusters of tiny bubbles if the implosive collapse is violent-enough. Clearly, bubble cluster shape and form can change in a complex manner if the drive amplitude or if the pressure amplitude of the test chamber changes. It has been reported (Nigmatulin et al., 2004; Taleyarkhan et al., 2004b) that spherical bubble collapse can lead to sig- nificantly more intensified implosions than other configurations involving aspherical collapses of bubbles. Therefore, scoping efforts were made to image the evolution of bubble clusters (using a 5000 fps camera) and relate the behavior with shock trace magnitudes to develop possible insights into the complexities involved. It was found that under nominal operating conditions (at \pm 15 bar drive amplitude and test liquid at $\sim 0{ }^{\circ} \mathrm{C}$ ) the bubble cluster formation is largely spherical and lasts for about $5 \mathrm{~ms}$. The higher the test liquid temperature, the longer is the life time for the bubbles before they re-dissolve into the bulk liquid (Taleyarkhan et al.,2004b). Fig. 6 shows a typical evolution of bubble clusters under nominal operating conditions for normal acetone (for which the temperature was $\sim 4{ }^{\circ} \mathrm{C}$ ). It is seen that the bubble cluster shape is largely spherical for up to about $3.6 \mathrm{~ms}$, after which the bubble cluster starts to lose its spherical shape and tends to dis- 


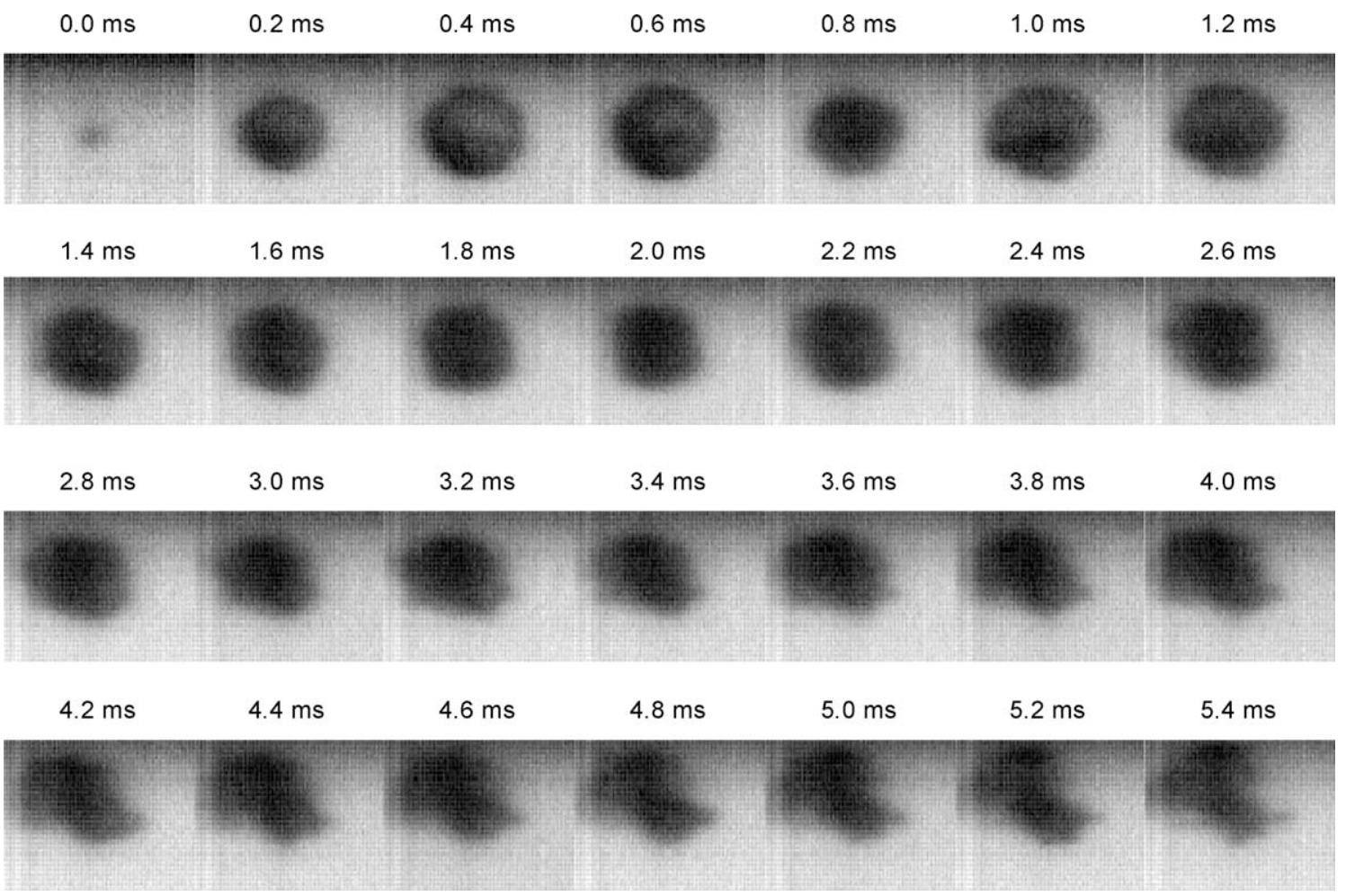

Fig. 6. Individual bubble cluster $\left(\mathrm{C}_{3} \mathrm{H}_{6} \mathrm{O}, 4{ }^{\circ} \mathrm{C}, \sim \pm 17\right.$ bars, $\left.16.7 \mathrm{kPa}\right)$.

perse and condenses back into the liquid. On the other hand, experience also indicated that under certain operating conditions the formation of imploding spherical bubble clusters can change radically to form streamers (comet-like structures) shown in Fig. 7. Such cometlike structures can last for several tens of milliseconds and appear to play a critical role in terms of their ability to induce bubble nuclear fusion.

The transition from spherical bubble cluster shape to the formation of comet-like structures was accompanied with stark changes in the recorded intensity of the shock waves (recorded by the glass-wall mounted

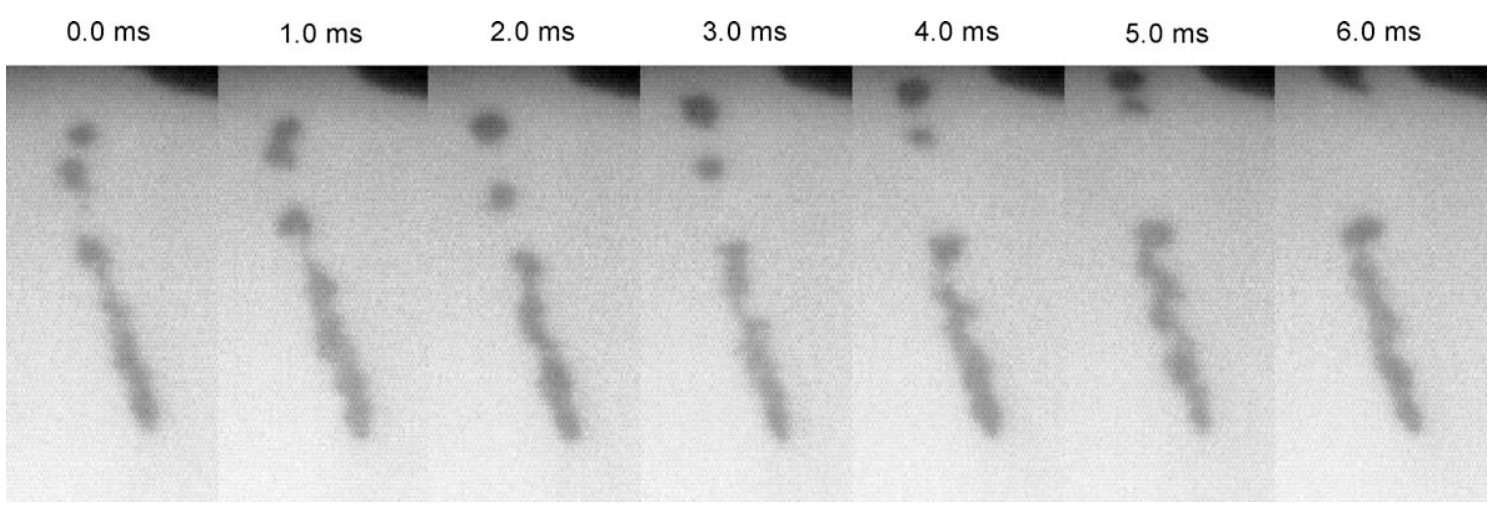

Fig. 7. Comet-like streamers $\left(\mathrm{C}_{3} \mathrm{H}_{6} \mathrm{O}, 4^{\circ} \mathrm{C}, \sim \pm 17\right.$ bars, $\left.16.0 \mathrm{kPa}\right)$. 


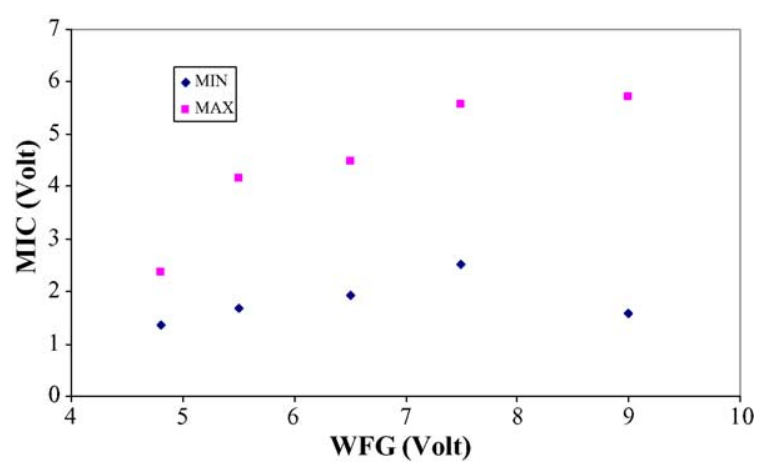

Fig. 8. Amplitudes of microphone signals with increase in drive amplitude.

microphone) - an indirect indication of implosion intensity. Fig. 8 depicts the behavior of mechanical impact-induced shock trace amplitude recorded by the microphone attached to the glass walls of the test chamber. As clearly noted, increasing the drive power from the amplifier initially increases the recorded shock trace magnitude. However, the process is non-linear. Beyond a certain power level the magnitude of shock waves levels off, and indeed, if the bubble clusters turned to comet-like structures no shock traces were recorded and the amplitude of the microphone signals dropped precipitously. These observations provide engineering insights into the tritium emission data from neutronseeded acoustic cavitation with $\mathrm{C}_{3} \mathrm{D}_{6} \mathrm{O}$ wherein the presence of streamers also resulted in a null-result. However, this conclusion can only be considered as preliminary and more work is clearly needed to understand all the complexities of bubble cluster formation and evolution.

\section{Conclusions}

Statistically significant emissions of tritium and neutrons were measured during neutron-seeded acoustic cavitation experiments with chilled deuterated acetone. Excess neutrons were found to be $\leq 2.45 \mathrm{MeV}$ in energy. Control experiments with normal acetone and experiments with neutron irradiation alone did not re- sult in statistically significant neutron nor tritium emissions.

\section{Acknowledgments}

The authors gratefully acknowledge the advice, guidance and assistance from Professor Rusi P. Taleyarkhan and Dr. J.S. Cho of Purdue University and Oak Ridge National Laboratory for design and setting up of the acoustic test cell. Also acknowledged is the supervision of tritium data analysis from Professor S.T. Revankar of Purdue University, the timely support provided by J.C. Walter of Purdue University and Dr. J. Schwietzer of Purdue University's Radiological and Environmental Services (REMS). The authors would like to recognize the encouragement and useful comments provided by Professor G. Lohnert which were helpful for improving the quality of this manuscript.

\section{References}

Brennan, C.E., 1995. Cavitation \& Bubble Dynamics. Oxford University Press, New York.

Camara, C.,Putterman, S., Kirilov, E., 2004. Sonoluminescence from a Single Bubble Driven at $1 \mathrm{MHz}$, vol. 92. PRL, p. 12.

Crum,L., Matula, T., 1997. Shocking revelations. Science 276, 1348.

Gross, R.A., 1984. Fusion Energy. John Wiley and Sons.

Hahn, B., 1961. Nuovo Cimento, 22, pp. 650.

Harvey, J., Hill, N., 1979. Nucl. Instrm. Methods 162, 507.

Moss, W.C., Clarke, D.B., White, J.W., Young, D.A., 1996. Sonoluminescence and the prospects for table-top microthermonuclear fusion. Phys. Lett. A 211, 69-74.

Nigmatulin, R.I., Taleyarkhan, R.P., Lahey Jr., R.T., 2004. Evidence for nuclear emissions during acoustic cavitation - revisited. Proc. Inst. Mech. Eng.. Journal of Power and Energy, Part A 218, 345-364, Special Issue.

Taleyarkhan, R.P., West, C.D., Cho, J.S., Lahey Jr., R.T., Nigmatulin, R.I., Block, R.C., 2002. Evidence of nuclear emissions during acoustic cavitation. Science 295, 1868-1873.

Taleyarkhan, R.P., Cho, J.S., West, C.D., Lahey Jr., R.T., Nigmatulin, R.I., Block, R.C., 2004a. Additional evidence of nuclear emissions during acoustic cavitation. Phys. Rev. E 69, 036109.

Taleyarkhan, R.P., Lahey Jr., R.T., Nigmatulin, R.I., 2004b. Bubble Nuclear Fusion Technology-Status and Challenges. In: Proceeding of Japan-US Seminar on Two-Phase Flow Dynamics, vol. 2, Nagahama, Japan, December 6-11, pp. 1-32. 